
преподаватель

\title{
ОШИБКИ И КОРРЕКТИВНАЯ ОБРАТНАЯ СВЯЗЬ: СОВРЕМЕННАЯ ТЕОРИЯ ОБ ОШИБКАХ И ИХ ИСПРАВЛЕНИИ НА ПРАКТИЧЕСКИХ ЗАНЯТИЯХ
}

У статті розглянуто сучасний толерантний підхід до виправлення помилок на практичних заняттях з іноземної мови.

В своей книге «Ошибки и коррекция» английский лингвист Джулиан Эдж пишет, что когда мы, преподаватели, решаем исправить наших студентов, «мы должны быть уверены в том, что используем коррекцию позитивно во благо обучения».

Возможно, преподаватели иностранных языков во многом согласятся со мнением Эджа, но сомнение вызывает способ исправления ошибок, допускаемых в разговорной речи нашими студентами.

Мы видим постепенный сдвиг на практических занятиях от мгновенного исправления каждой ошибки в более старых методиках, основанных на бихевиористических теориях обучения (аудиолингволизм) к более толерантному современному подходу. И все же исправление ошибок остается одним из самых спорных вопросов в обучении иностранным языкам как профессии.

Современная теория и методика обучения языкам придерживаются позиции, что не все ошибки должны быть исправляемы, а те, которые исправляются, не должны рассматриваться немедленно. Эта позиция основывается на том факте, что ошибки - это нормальное и неизбежное явление в процессе обучения.

Ошибки возникают по многим причинам. Одна из очевидных причин - влияние родного языка. Обучаемый может делать ошибки, потому что он допускает, что изучаемый язык и родной язык подобны, тогда как они различны. Другой очевидной причиной являются просто неполнота знания изучаемого языка. Третья общая причина - это сложность языка как предмета. Определенные вопросы грамматики английского языка (например, окончание - $\mathrm{s}$ - в третьем лице единственного числа настоящего простого времени) являются трудными для всех студентов, независимо от того, каков их родной язык. Орфография также проблематична для тех, для кого английский язык является неродным (а также для многих носителей языка!). 
И, наконец, возникает некий консерватизм, когда человек достигает удовлетворительного уровня владения вторым языком и не беспокоится о постоянных ошибках, которые может делать, так как они не мешают общению.

\section{Что такое ошибка?}

С этой точки зрения рассмотрим по порядку несколько определений. Английский лингвист Г. Д. Браун предлагает следующие отличия:

«Ошибка (a mistake) - это то, что имеет случайный характер или оговорка, обмолвка». Согласно этому определению, носитель языка может сделать такую ошибку и в родном языке.

Ошибки (errors) - это такие проблемы, которых не будет у носителей родного языка. По определению Брауна, «ошибка (an error) - это заметное отклонение от грамматики взрослого носителя языка, отражающее внутриязыковую компетенцию обучаемого».

Ключевое понятие в этом определении - это «внутриязыковой». Когда кто-то изучает иностранный язык, ошибки, которые он допускает, указывают на его уровень умений и навыков. Ясно, что ошибки начинающего отличаются от ошибок студента на продвинутом этапе (то, что было errors, может стать всего лишь mistakes).

Эдж предлагает более простые определения, которые особенно важно помнить в аудитории. Он говорит, что a slip - это то, что обучаемый может исправить сам, a an error - то, что обучаемый не может исправить сам.

Указанные отличия между error и mistake или между error и slip являются достаточно обоснованными, чтобы прекратить практику немедленного исправления студентов. Часто хватает короткой паузы или невербального намека, чтобы студенты поняли и затем исправили ошибки, которые они допустили в речи.

Уильям Энкер, научный сотрудник из госдепартамента США по вопросам обучения английскому языку, работая с преподавателями английского языка в Латинской Америке, Африке, Средней Азии и на Кавказе, выяснил, что большинство из них меняют подход к ошибкам на более толерантный. Они уже не исправляют своих студентов автоматически. Вместо этого они поощряют самоисправление и исправление другими студентами. Они менее озабочены предотвращением ошибок, а больше сфокусированы на развитии коммуникативных навыков обучаемых. Однако многие студенты все еще ждут, даже просят, чтобы преподаватель исправлял все их ошибки.

Чтобы выяснить, отличаются ли мнения преподавателей по вопросу исправления ошибок от ожиданий студентов, Уильям Энкер проводил ряд исследований. За 4 года в 15 странах он опросил многих преподавателей и студентов, задав вопрос: «Должны ли преподаватели исправлять каждую ошибку, которую допускают студенты, говоря по-английски?». 
Самой частой причиной нежелания исправления было негативное влияние исправления на уверенность студента в себе и на мотивацию. Самой частой причиной желательного исправления была важность научиться правильно говорить по-английски.

Самые частые причины, почему преподаватели не должны исправлять каждую ошибку:

1. Исправление может развить нечто в виде барьера, и студенты будут бояться делать ошибки и не будут говорить или изучать английский с удовольствием (преподаватель из Киргизии).

2. Если преподаватели исправляют каждую ошибку, которую допускают студенты, студенты начинают ненавидеть их (узбекский студент).

3. Исправление каждой ошибки займет слишком много времени (преподаватель-стажер из Гватемалы).

4. Невозможно исправить каждую ошибку (преподаватель из Марокко).

5. Студенты забудут исправления (преподаватель из Казахстана).

Частые причины, почему преподаватели должны исправлять каждую ошибку:

1. Преподаватели должны исправлять ошибки для того, чтобы дать знать студентам, что неправильно, а что правильно (преподаватель из Грузии).

2. Студенты должны говорить, не боясь того, что они будут говорить с ошибками (армянский студент).

3. Если никто не будет исправлять наши ошибки, мы никогда не научимся правильному английскому (студент из Эквадора).

4. На каждую ошибку следует обращать внимание в тот момент, когда она допускается, иначе студенты будут продолжать делать те же самые ошибки (преподаватель из Колумбии).

5. Если преподаватель не исправляет ошибки, он не настоящий преподаватель (узбекский преподаватель).

Важнейший смысл этого исследования - исправить создавшееся положение, определиться в том, исправлять или нет ошибки. Одни преподаватели думают, что они делают правильно, не исправляя сразу же и часто. А другие преподаватели и студенты считают, что их учитель не знает английский язык достаточно хорошо, чтобы осуществить соответствующую обратную связь, или хуже того, что такой преподаватель - не профессионал и не заботится о том, чтобы учащиеся хорошо выучили иностранный язык.

Однако можно сделать несколько шагов, чтобы исправить эту ситуацию. Прежде всего, мы должны четко ставить цели в поурочных планах. Далее, можем обсудить процесс обучения с нашими студентами. И, в конечном счете, мы должны использовать альтернативные виды работы, которые демонстрируют другие способы установки обратной связи, кроме немедленного исправления преподавателем.

$$
-127-
$$




\section{Постановка целей урока}

Первый и самый важный шаг, который должен сделать преподаватель, - определить цель вида работы. Если цель - развивать точность, то, конечно, требуется коррекция. В этом случае наилучший подход - позволить студенту сначала исправить ошибки самому. Если это не сработает, позвольте его однокурсникам сделать это. Если окажется, что никто не знает, то преподаватель может дать исправленный ответ. Хотя может показаться, что это отнимает время, зато помогает сосредоточить внимание студентов и уменьшить их надежду на преподавателя, поощряет самостоятельность студента. Если цель работы - развивать беглость речи, то коррекция не обязательна и даже не желательна. Постоянное перебивание студентов с целью их исправления может вызвать раздражение и срыв, особенно если недостаток точности не мешает общению. Если ошибки слишком часты, преподаватель может отметить их в уме, чтобы обеспечить обратную связь после этого вида работы.

\section{Обсуждение процесса обучения}

Неисправление ошибок кажется возмутительным и даже безответственным некоторым педагогам и многим студентам. Однако, неисправление ошибки - это не то же самое, что обучение неправильным формам.

Мы можем объяснить основную причину нашего неисправления ошибок, даже если требуется использовать родной язык с тем, чтобы наши студенты лучше понимали, что мы делаем и почему мы это делаем, а в случае исправления ошибок, почему мы не всегда так делаем.

Можно использовать аналогию при обсуждении ошибок со студентами: обучение говорению на другом языке подобно обучению игре на музыкальном инструменте. Оба процесса требуют интеллектуальных усилий (изучение новых символов, запоминание), новых физических навыков (ловкость рук при игре на инструменте, произношение новых звуков в изучаемом языке) и огромной практики. Никто не думает научиться музыке, не делая ошибок в процессе обучения. Тогда как можно научиться языку, не произнося не единой ошибки?

Эффективным способом демонстрации недоверчивым студентам того, что ошибки являются обычной и неизбежной частью процесса обучения, является юмор.

Каждый изучающий иностранный язык нечаянно делает смешные ошибки. Приведем несколько примеров: «Мимо дома стоит машина». «У нас часто ходит дождь». «На подоконнике стояла подстольная лампа». «В нашей стране разбивается гражданская авиация».

Дети делают ошибки, и мы считаем их остроумными. Почему же тогда подростки и взрослые студенты чувствуют себя так неловко? Очевидно, наша собственная реакция влияет на уровень поддержки наших студентов. Если мы хотим, чтобы они были толерантными, то мы должны сами

$$
-128-
$$


вести себя толерантно, воздерживаться от стремления автоматически и немедленно исправлять ошибки. Полезно также краткое межъязыковое объяснение. Хотя не все преподаватели придерживаются этой крайней точки зрения, опыт часто показывает, что исправление ошибок, которые выходят за уровень понимания обучаемого, может прервать урок и вызвать больше неловкости, чем ясности.

В конечном счете, нам нужно переместить внимание наших студентов и наше собственное на позитивные аспекты ошибок. Ошибка показывает, что обучаемый должен исправлять свои речевые недочеты. Игнорировать успехи наших студентов и преувеличивать серьезность ошибок - интеллектуально нечестно и непродуктивно.

\section{Альтернативные виды работы}

Конечно, никто не собирается обучать иностранному языку неправильно, поэтому понятно, что наши студенты часто обращаются к нам для обеспечения обратной связи. Однако, как знают все опытные преподаватели, коррекция не всегда срабатывает. Студенты могут повторить ту же ошибку и после того, как она была исправлена.

Иногда можно сорваться, но можно и тактично указать на ошибку, когда она возникает, повторить исправленный вариант. Но когда мы сфокусированы на значении, то, естественно, стремимся не обращать внимания на второстепенные проблемы. Хотя попытки студентов могут быть неверными, их нужно поощрять делать логические предположения в отношении новых слов и конструкций изучаемого языка. Например, можно подготовить работу на базе сходных и заимствованных слов, дать возможность попрактиковаться, чтобы поощрить этот тип стратегии вознаграждения, а не стратегии избежания. Мы можем помочь нашим студентам развить интуицию в области английского языка, делая контрастный анализ первого и второго языка (особенно фонологии и синтаксиса). Можем поднять несколько самых трудных вопросов английской грамматики, произношения и орфографии, чтобы убедить студентов в сложности изучаемого материала.

Опытные преподаватели знают, что студенты часто исправляют друг друга, не подсказывая. Мы можем способствовать развитию этого типа сотрудничества, обсуждая и перечисляя вежливые способы обратной связи. В то же время мы можем пояснить, что считается невежливым. Обращаясь к спорным вопросам, мы помогаем студентам развивать их социолингвистическую компетенцию в английском языке.

Было бы упрощенным считать, что в области исправления ошибок достигнут консенсус. Многие преподаватели и студенты все еще предпочитают немедленное исправление преподавателем в аудиолингвальном стиле, несмотря на недостаток эффективности и его карательную природу. Мы можем обращаться к нашим студентам и говорить им на метапознавательном уровне об ошибках и их коррекции. Такая дискуссия поможет им лучше понять процесс обучения языкам и наши методы преподавания.

$$
-129-
$$




\section{Список использованной литературы}

1. Bartram, M., and R. Walton. Correction: A positive approach to language mistakes. Hove: Language Teaching Publications. - 1991.

2. Edge, J. Mistakes and correction. London: Longman. - 1989.

3. Ancker, W. Errors and corrective feedback: updated theory and classroom practice. English Teaching Forum. - 2000.

\section{Summary}

The article deals with updated theory on errors and correction. Error correction is one of the most contentious issues in foreign language teaching profession. 